\title{
Digital Transformation of the Economy and Industry: Problems and Prospects
}

\author{
A. Salamova ${ }^{1, *}$, L. Khatsieva ${ }^{2}$, Kh. Gishlakaeva ${ }^{3}$ \\ ${ }^{1}$ Chechen State University named after A.A. Kadyrov, Grozny, Russian Federation \\ ${ }^{2}$ Grozny State Oil Technical University named after Academician M.D. Millionshchikova, Grozny, Russian \\ Federation \\ ${ }^{3}$ Chechen State College of Economics, Grozny, Russian Federation \\ *Corresponding author. Email: salamova_chgu@mail.ru
}

\begin{abstract}
The emergence of completely new growth factors, new drivers of economic development, the rapid pace of technological change, a high degree of uncertainty caused by the high speed of ongoing changes and the emergence of new megatrends, new threats require the formation of a new philosophy of substantiating management decisions, new approaches to the formation of strategies and development programs. Only radically different approaches will make it possible to turn new threats into new opportunities. "There are several key simultaneously developing trends. It is not possible to avoid their impact and we are facing their consequences now. Organizations that can adapt to these trends and understand how to turn them into perspectives will succeed," said Blair Sheppard, Team Leader, Strategy and Leadership, PwC USA.
\end{abstract}

Keywords: economic development, new opportunities, developing trends, new drivers, technological changes, strategy formation.

\section{INTRODUCTION}

Building a digital economy, digital transformation in the market, the use of new digital business models is impossible without a systematic approach to innovative activities of organizations in all areas of activity. The diversity of the environment causes such a basic reference point as the freedom of action of the organization in the market, which is promoted by marketing innovations [1]. Leading countries have already set themselves the task of creating a new digital economy, which implies the digital transformation of enterprises. Russian business must also prepare for the introduction of new digital business models, for adaptation in a new competitive digital environment. There are factors that give the potential for the formation of a digital economy in Russia, but the question remains about their effective implementation, that is, demand and distribution factors, as well as institutional factors remain the main "pain points" in the Russian economy.

There is a digitalization of economic processes and the penetration of information technologies into all spheres of activity. There are new requirements for the sources of competitive advantages of enterprises and effective concepts of their functioning and management. An effective tool for implementing acts of intelligent control on a hard real-time scale is the class of temporal models based on knowledge and capable of operating with information of a dynamic and fuzzy nature [2]. For the case where information cannot be estimated numerically, but is determined by inaccurate knowledge expressed in natural language and based on intuition, the experience of decision-makers, this approach has an obvious advantage over traditional models that use clear estimates.

\subsection{The main directions of development of "Industry 4.0"}

Currently, research has been carried out in the field of developing directions for the development of Industry 4.0. Analysis and evaluation of these studies in terms of the frequency of references in the reviewed publications allows us to highlight the main areas of Industry 4.0 (Table 1). Cyber-physical systems are based on a conceptual approach of the possibilities of integrating information resources and production resources of an enterprise (or several enterprises) for interaction in 
Table 1. The main directions of "Industry 4.0" (ranked by frequency of mentions in publications).

\begin{tabular}{|c|c|c|}
\hline Studied concepts & $\begin{array}{l}\text { Share of mentions in the } \\
\text { surveyed publications }(\%)\end{array}$ & Ranks \\
\hline Cyber-Physical Systems - Cyber-Physical-CPS & 29,7 & 1 \\
\hline Internet of Things - Internet of Things - IoT & 23,2 & 2 \\
\hline Smart Enterprise - Smart Factory & 15,5 & 3 \\
\hline Smart services - Internet of Services & 12,3 & 4 \\
\hline Smart Products - Smart Product & 6,5 & 5 \\
\hline Mechanisms with mechanisms - Machine to Machine - M2M & 5,2 & 6 \\
\hline Big Data - Big Date & 4,5 & 7 \\
\hline Cloud technologies - Cloud & 3,1 & 8 \\
\hline
\end{tabular}

management, planning, marketing, self-tuning, adaptation to changes, which makes it possible to ensure the creation of the Internet of Things, focused on the creation of "smart systems "that enter the Internet without human intervention (" smart home "," smart car ", etc.). So, according to Cisco, by 2020. 50 billion various devices and objects will be connected to the Internet (in 2010 - 12.5 billion were connected, in 2015 - 25 billion). Smart factories must become a key factor in the production system in which mechanisms interact with each other. Big Data allows you to have large information arrays, systematize them, use them in modeling the life cycle of a product, assessing new models of consumer behavior, forming new approaches to logistics and marketing.

Professor Wolfgang Walster, General Director of the Research Center for Artificial Intelligence (Germany) believes that "Cyber-physical systems will fundamentally change the traditional logic of production, since each work object will determine for itself what work needs to be done. The ability of machines to understand a certain situation will lead to a completely new level of quality in industrial production. The interaction between a large number of individual components will enable the development of a solution that was previously impossible to program in production plants. " Thus, "Industry 4.0." "Lifelong learning"), focused on the formation of competencies, adequate to the ongoing changes. Against the background of exploring new opportunities, opinions emerge that focus on the potential challenges and threats of Industry 4.0. The analysis of the materials of the Davos forums - 2016 and 2017 made it possible to identify the following main trends that change technological, innovative and economic development in the context of the 4th industrial revolution: 1) digitalization - the development of digital technologies; unification of the real and virtual world; (everything is numbered, everything is networked);

2 ) the return of branches and companies that were transferred by the technology leaders to other countries due to cheap labor, again to developed countries as a result of the development and benefits of digitalization (salary costs are significantly reduced, focus is on new competencies);

3) the ability to create joint innovations (Klaus Schwab), new forms of organization of production; new technologies change supply and demand, create new needs and opportunities.

Thus, digitalization will fundamentally change the economic and innovation landscape. According to the forecast, by $2035.95 \%$ of production processes will be automated, and $50-70 \%$ of jobs will cease to exist. The widening gap between the level of economic and technological development of different countries, as well as different groups of the population, depending not only on the level of economic well-being, but also on the ability to actively participate in the process of digitalization, use intellectual property, be innovatively active lead to an increase in the threat of being hit into the "trap of growing technological lag", the implementation of the negative consequences of the Concept for the development of the "technological abyss", which undermines the national security of the country and creates new global risks. The processes of digitalization of the armed forces create threats to the development of new types of weapons, operating without direct human participation, and a manifold increase in the capabilities of the person himself, which can lead to an exacerbation of military conflicts and the unpredictability of their results $[2,4]$.

Table 2. Areas of activity in which the European Technology Platforms are established European Technology Platforms - ETP.

\begin{tabular}{|l|l|}
\hline Field of activity & Number of platforms \\
\hline Energy & 7 \\
\hline Information and communication technologies & 9 \\
\hline Bioeconomics & 6 \\
\hline Industry & 9 \\
\hline Transport & 5 \\
\hline Total & 36 \\
\hline
\end{tabular}




\section{RESULTS AND DISCUSSION}

New megatrends in the technological and economic development of Industry 4.0 dictate the need to change the innovation landscape. In our opinion, although "Industry 4.0" is called the "Fourth Industrial Revolution" differently, changes should take place evolutionarily at the following levels: conceptual, based on the development of new approaches to managerial decision-making, focused on new decision-making models, strategic, providing justification of priority areas development, program documents that provide a "new vision" of the future, but, in addition, the solution of priority tasks that should be aimed at creating an institutional environment favorable for the formation of "Industry 4.0" level of innovative development. Currently, a new institutional environment is being formed that is conducive to innovative development and new organizational structures. The most important changes in the innovation landscape include (for example, the EU): - European Technology Platforms (ETP) [11]; - European Industrial Initiatives (EII) [11]; European Innovation Partnerships; - State partnerships (Joint Programming Initiatives) [5]; - Cluster-network structures of the European Institute of Innovation and Technology (Knowledge and Innovation Communities (KICs) of the European Institute of Innovation and Technology (EIT)) [9,10];

- European Business Innovation Network (EBN) [12]; - the possibility of using crowdsourcing platforms [13]; - Technology anc jnnovation Support Centers providing services to the World Intellectual Property Organization (WIPO). Table 2 shows the areas of activity in which the European technology platforms are implemented [9]. The technology for creating European technological platforms has been developed, it consists of the following stages:

1) combining the interests of stakeholders in order to form a long-term development strategy (Strategic vision document, SVD);

2) development of the Strategic Research Agenda (SRA), as well as the development of the Working program for the implementation of the strategic plan (Working program) for the year;
3) implementation of the Strategic Research Plan with the involvement of mechanisms and tools of EU scientific programs.

Advanced technology platforms have so-called "mirror groups", which are supposed to provide a link between platform activities and product creation at the national and regional level. A number of technology platforms in the EU are already in the third phase: the implementation of the strategic research plan. European unified technological platforms unite the efforts of private business (both large and small), scientific and educational organizations, public and state bodies, which allows the creation of joint public-private projects (programs) - joint technological initiatives (Joint Technological Initiative - JTI) [ 10.11].

Joint technological initiatives (Table 3 ) are aimed at implementing the program in key technological and innovative areas, the amount of funding for which is 10 billion euros, of which 1/3 is represented by the European Commission, and the rest - by research, industrial organizations, foundations, etc. The first 5 programs on joint technology initiatives have been allocated more than 3 billion euros over a five-year period [7].

\section{CONCLUSION}

Any complex open dynamic system develops both by slow evolution and by leaps from one quality to another. The dialectics of the development and functioning of open systems consists in the sequential change of such quantities as the coefficient of adaptation of the system and the coefficient of sensitivity of the system to changes in the external environment [9]. The economy is an open dynamic system and its evolutionary development is interrupted by revolutionary leaps. So, since the end of the 18th century, three industrial revolutions have occurred in the economy, and developed countries are facing the beginning of the fourth industrial revolution associated with the formation of the digital economy, the widespread introduction of information and communication technologies, and the transition to new digital business development models [11].

Changes in the external environment require a response from the organization's protection system. Any organization should compare not only the coefficient of adaptation of the system and the coefficient of sensitivity of the system to changes in the external environment, as

Table 3. Joint Technology Initiatives - JTI.

\begin{tabular}{|l|l|}
\hline Scope and directions of activities of the joint technology initiative Amount of funds allocated, billion euros \\
\hline Biomedicine (IMI) & 1 \\
\hline Embedded Computer Systems (ARTEMIS) & 0,41 \\
\hline Economical Air Transport (Clean Sky) & 0,8 \\
\hline Nanoelectronics (ENIAC) & 0,45 \\
\hline Fuel Cells and Hydrogen (FCH) & 0,47 \\
\hline Biomedicine (IMI) & 1 \\
\hline Embedded Computer Systems (ARTEMIS) & 0,41 \\
\hline
\end{tabular}


indicated above, but also compare the speed of management and the speed of the emerging threat [4]. If the latter value exceeds the first or the indicator of their division is less than one, then the organization will be in danger and innovative decisions must be made at the management level, a transition to new business development models must be made. Management innovations, which are changes in the organization's management system in order to increase the efficiency of its functioning and adaptability to changes in the composition of its environment, are implemented through a change in the technology and organization of the management process, in particular, the decisionmaking process. The focus on the stream structure aims management innovation at overcoming intraorganizational boundaries in order to adapt to changes in the external environment. Consistency predetermines that management has a pronounced cyclical nature and that, in turn, affects the generation of management innovations. A systematic approach to managerial innovation allows the leader to more productively implement his main functions: forecasting, planning, organization, decision-making and control [11]. The basic guideline of an organization with such a property of the external environment as other organizations is coexistence. Organizations operating in conditions of uncertainty of the market environment, rather tough competition, should have as complete information base as possible for timely prompt management decisions that improve the company's image and financial results. In this regard, the validity of the existence of such a concept as "information innovation" appears, although information technologies are used to implement all other types of innovations [5]. Information stands out as an independent resource in the study of innovative activity, because it is here that new knowledge becomes the main factor in the management process [2]. The complexity and dynamism of modern technological processes, information flows, a significant amount of work on the collection and processing of information determine the increased requirements for the organization of management of the enterprise as a whole, for the availability of analytical competencies among managers.

\section{REFERENCES}

[1] D. G. Gaynulin, V. V. Voronin, General principles of forming a risk management system in the field of economic security, 2018 p. 154.

[2] A. Braverman, A. Saulin, Integral assessment of enterprise performance, 2019 pp. 108-121.

[3] R. Brailey, S. Myers, Principles of Corporate Finance 2020 p. 132.

[4] A. Voronov, S. Rubanov, Sustainable development of the enterprise as a strategic goal of marketing, 2018 pp. 31-37.
[5] E.V. Korchagina, Economic sustainability of an enterprise: types and structure. Problems of the modern economy 3(15) (2018) pp. 68-71.

[6] Campbell Scientific Inc., Bowen Ratio system. Instruction manual. Logan, UT USA 2020 p. 30.

[7] W.A. Dugas, Micrometeorological and chamber measurements of $\mathrm{CO} 2$ flux from bare soil Agricultural and Forest meteorology, 2018 pp. 115128.

[8] A.S. Salamova, The theoretical foundations of institutionalism at the stage of accelerating globalization of international economic relations, 2020 pp. $349-356$.

[9] J.J. Andrea, C. Burns, J. Touza, Renewable Energy as a Luxury? A Qualitative Comparative Analysis of the Role of the Economy in the EU's Renewable Energy Transitions During the 'Double Crisis'. Ecological Economics 142 (2020) pp. 81-90.

[10] J. Yang, F. Zhang, X. Jiang, W. Sun, Strategic Flexibility, Green Management, and Firm Competitiveness in an Emerging Economy. Technological Forecasting and Social Change 101 (2018) pp. 347-356.

[11] K. Murtazova and M. Abdulkadirova, The Consumer Market in the New Economy, 2021 pp. 29. 